\title{
Pembangunan Sistem Electronic Customer Relationship Management (E-CRM) pada PT. Sapta Satria Jaya
}

\author{
TRI WIJAYA PERMANA SIDIK ${ }^{1}$, WINA WITANTI ${ }^{2}$, FAJRI RAKHMAT \\ UMBARA $^{3}$ \\ 1,2,3 Universitas Jenderal Achmad yani \\ triwijayajack@mail.com
}

\begin{abstract}
ABSTRAK
PT. Sapta Satria Jaya merupakan perusahaan di bidang jasa keamanan outsourcing dengan sistem kontrak. Pengolahan keluhan terhadap client yang akan dijadikan laporan masih tidak efektif karena laporan dari setiap Danru masih ditulis di kertas sehingga kantor pusat harus membuat format laporan ulang untuk diberikan kepada client setiap 1 bulan sekali. Electronic-Customer Relationship Management (E-CRM) merupakan sebuah strategi yang digunakan oleh suatu organisasi atau perusahaan untuk dapat menciptakan dan mempertahankan suatu hubungan yang baik dan berkelanjutan dengan client dan mengurangi kemungkinan para client pindah ke perusahaan lain. Penelitian ini bertujuan untuk membangun sebuah Electronic Customer Relationship Management (E-CRM) yang berbasis website dan mobile web pada PT. Sapta Satria Jaya agar dapat menjalin hubungan dan meningkatkan pelayanannya kepada client. Pengembangan sistem penelitian ini menggunakan model waterfall. Penelitian ini akan menghasilkan sebuah Sistem Electronic Customer Relationship Management (E-CRM) berbasis website dan mobile web yang kemudian akan diuji dengan menggunakan metode pengujian Black-Box , yaitu menguji perangkat lunak dari segi spesifikasi fungsional tanpa menguji desain dan kode program, dengan pembangunan Electronic-Customer Relationship Management (E-CRM) ini diharapakan PT. Sapta Satria Jaya dan menjalin hubungan yang berkelanjutan dan dapat meningkatkan layanannya kepada client apabila selesai diimplementasikan diharapkan menurunkan presentasi keterlambatan Danru menjadi 10\%.
\end{abstract}

Kata kunci: Client, E-CRM, Waterfall, Satpam. 


\section{PENDAHULUAN}

Perkembangan teknologi saat ini berkembang dengan cepat agar dapat bertahan dalam persaingan tersebut, suatu perusahaan dituntut memiliki sifat kreatif yang harus selalu siap dalam menghadapi perubahan pasar yang selalu berubah, maka perusahaan akan berusaha mempertahankan pelanggannya supaya tidak direbut oleh perusahaan lain hal ini akan berdampak pada tingginya tingkat persaingan antar perusahaan dalam meraih client. Rancangan sistem berbasis website dan mobile web dapat membantu perusahaan dalam mendapatkan client baru, serta mendukung proses pelayanan terhadap client yang efektif sehingga dapat membantu perusahaan dalam mencapai visi dan misi. (Agung et al, 2009). Perusahaan yang akan dijadikan tempat penelitian adalah perusahaan bergerak di bidang jasa atau outsourcing, didefinisikan sebagai sebuah proses memindahkan kegiatan usaha ke pihak ke tiga, tujuan utama melakukan outsourcing adalah untuk menghemat biaya produksi. Cara untuk mengehemat biaya produksi perusahaan adalah mengalihdayakan kegiatan usaha (Jafari, 2016).

Komunikasi dengan pelanggan pada perusahaan untuk meningkatkan keuntungan dengan menggunakan E-CRM (Electronic CRM) yaitu usaha mengelola hubungan antara perusahaan dengan pelanggan dalam peningkatan kepuasan menggunakan produk yang diproduksi oleh perusahaan dengan memanfaatkan peralatan elektonik seperti TV, Telepon dan Internet (Mardison, 2015). Dalam mempertahankan pelanggan atau memperoleh client baru, perusahaan memerlukan satu strategi yang tepat salah dengan konsep yang ditawarkan adalah E-CRM (Electronic Customer Relationship Management) sebagai fungsi terintegrasi pelayanan terhadap client yang bertujuan untuk meningkatkan kepuasan client dan terutama untuk mendapatkan, mempertahankan, dan meningkatkan jumlah client perusahaan sehingga dapat dikatakan bahwa kesuksesan dalam bisnis, terutama di bidang jasa yaitu pelayanan dan hubungan dengan client (Dudley et al, 2010).

PT. Sapta Satria Jaya berdiri pada tahun 2013 dan berlokasi Jl. Terusan Al-Fathu, Komplek. Linggahara 2 Blok G No. 6 Kab. Bandung 40911 Perusahaan yang bergerak di bidang badan usaha jasa pengamanan (BUJP) yaitu perusahaan penyedia dan penggelola jasa pengamanan sesuai permintaan perusahaan pemakai jasa, dan perusahaan jasa keamanan ini bersedia ditempatkan di pabrik, restoran, factory outlet, hotel, tempat ibadah, hiburan dan rekreasi, dan pemerintahan dengan sistem kontrak. PT. Sapta Satria Jaya ini memiliki client di kota Bandung dan setiap client mempunyai 1 (satu) Danru (ketua regu) dan mempunyai 1 koordinator wilayah yang bertanggung jawab atas semua pengawasan dan pekerjaan yang telah ditugaskan oleh kantor pusat.

Sistem E-CRM ini untuk memberikan informasi PT. Sapta Satria Jaya bergerak dalam bidang jasa keamanan kepada calon client yang baru (acquire) dan mengetahui informasi client perusahaan mana saja yang sering ada keluhan pada kinerja security yang menyebabkan client tidak puas terhadap kinerja anggota security, dengan banyaknya client kantor pusat dapat mengetahui informasi client mana saja yang sering mengalami keluhan dan menjadikan evaluasi bagi perusahaan untuk meningkatkan loyalitas client untuk ke depannya tidak ada keluhan yang sama terjadi pada client (retain). Data keluhan dari client yang disampaikan kepada Danru (ketua regu) dan koordinator wilayah (Korwil) itu dimasukkan ke dalam sistem E-CRM dan setiap 1 minggu akan menampilkan grafik client mana saja yang mengalami keluhan, sehingga Danru di setiap client dapat mengetahui evaluasi kinerja terhadap anggota security untuk meningkatkan loyalitas client (acquire \& Retain). Manager HRD di kantor pusat dapat mengontrol client dengan cara melihat dari sistem tentang keluhan dari dari client. Pembuatan laporan termasuk pelayanan perusahaan untuk 
meningkatkan loyalitas terhadap client yang akan diberikan setiap 1 bulan sekali itu dapat dicetak di sistem yang telah dimasukkan oleh setiap Danru dan koordinator wilayah.

Pengolahan data keluhan terhadap client yang akan dijadikan laporan tidak efisien karena laporan masih ditulis di kertas menjadikan $70 \%$ dari setiap Danru terlambat mengumpulkan laporan dan jalur birokrasi laporan harus terlebih dahulu diberikan kepada koordinator wilayah dan baru diberikan ke kantor pusat sehingga butuh waktu 1 sampai 3 hari dalam pembuatan laporan, mengakibatkan penumpukan laporan yang belum selesai. Pengawasan secara real time semua client untuk mengetahui client mana saja yang sering terjadi masalah masih harus menghubungi kepada setiap koordinator wilayah, dan dibutuhkan informasi perusahaan dalam bentuk website untuk menyampaikan kualitas perusahaan (company profile).

Berdasarkan pada permasalahan yang ada, maka tujuan penelitian ini adalah membuat rancangan sistem E-CRM yang berisikan informasi perusahaan untuk calon client, pembuatan laporan secara sistem, pengontrolan secara real time oleh kantor pusat client mana saja yang sering terjadi keluhan dengan grafik, dan mengolah keluhan client sehingga dapat mengetahui dan menjadikan evaluasi bagi perusahaan.

Dalam melaksanakan penelitian ini diperlukan suatu batasan-batasan agar lebih fokus serta tidak menyimpang dari yang telah direncanakan, batasan-batasan tersebut yaitu :

1. Penelitian menangani implementasi rancangan sistem E-CRM (tahap acquire, tahap retain, dan tahap enhance).

2. Penelitian menangani pelayanan terhadap client dan calon client baru.

3. Penelitian ini menggunakan konsep Operasional CRM.

\section{METODE PENELITIAN}

Metode penelitian yang dilakukan pada penelitian ini bertujuan untuk mengetahui mengenai tahapan yang akan dilakukan. Perancangan sistem yang dibangun ini menggunakan metode waterfall yang dimana pada metode ini memiliki beberapa tahap, terdapat pada Gambar 1 (Wina Witanti A. A., 2009).

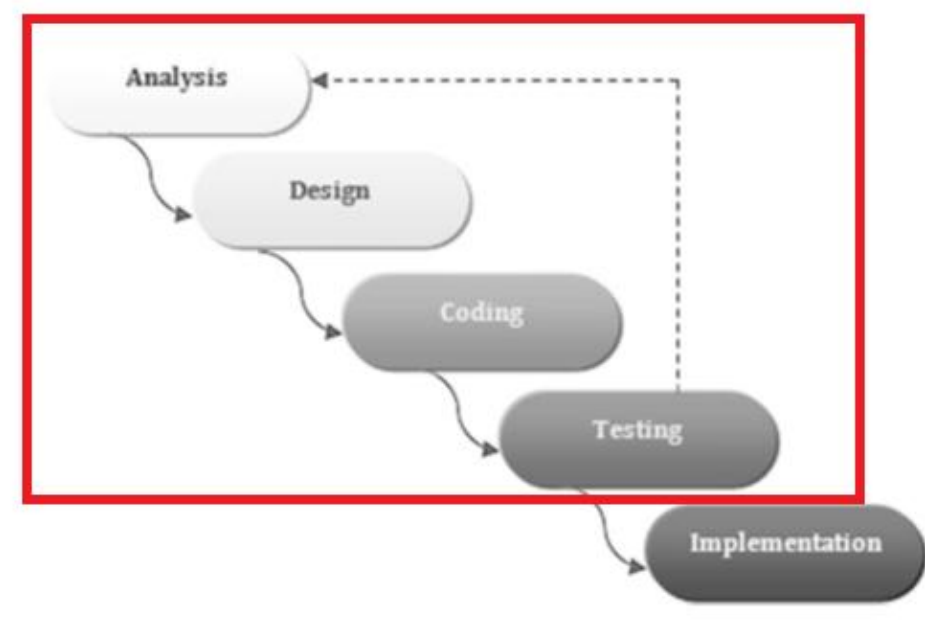

Gambar 1. Tahap Metode penelitian 


\subsection{Analysis}

Tahap ini bertujuan untuk analisis sistem yang diharapkan oleh pengguna dan batasan sistem yang akan dibangun. Pada tahap ini juga akan dilakukan analisis sistem berjalan pada perusahaan sehingga dapat diketahui secara garis besar fungsi apa saja yang akan dibuat dalam sistem. Perolehan data awal dilakukan dengan cara observasi atau datang dan menganalisis langsung pada perusahaan. Kemudian, dilakukan wawancara pada pihak yang berkaitan untuk mendapatkan data yang dibutuhkan (nima jafari, 2016) (Mardison, 2015).

\subsubsection{Observasi}

Metode ini melakukan pengamatan dan pencatatan mengenai apa saja yang ada pada PT. Sapta Satria Jaya saat ini, baik dari sistem yang digunakan maupun kegiatan yang mencakup proses bisnis dalam pengelolaan data client perusahaan.

\subsubsection{Wawancara}

Metode ini merupakan proses tatap muka secara langsung dengan salah satu pihak dari PT. Sapta Satria Jaya yang bertanggung jawab atas pelayanan client, maupun dengan pihakpihak lain yang terlibat dengan proses layanan client untuk memperoleh informasi secara langsung disertai dengan adanya data yang akurat.

\subsection{Design}

Berdasarkan pada analisis kebutuhan yang telah dilakukan sebelumnya, maka dalam tahap ini akan dilakukan persiapan desain dari sistem yang akan dibangun. Desain Sistem membantu dalam menentukan perangkat keras (hardware) dan membantu dalam mendefinisikan arsitektur sistem secara keseluruhan. Desain sistem akan digambarkan dalam Unifed Modeling Language (UML) (Fajri Rakhmat U, 2015). Sistem yang akan dibangun secara singkat terdapat pada Gambar 2.

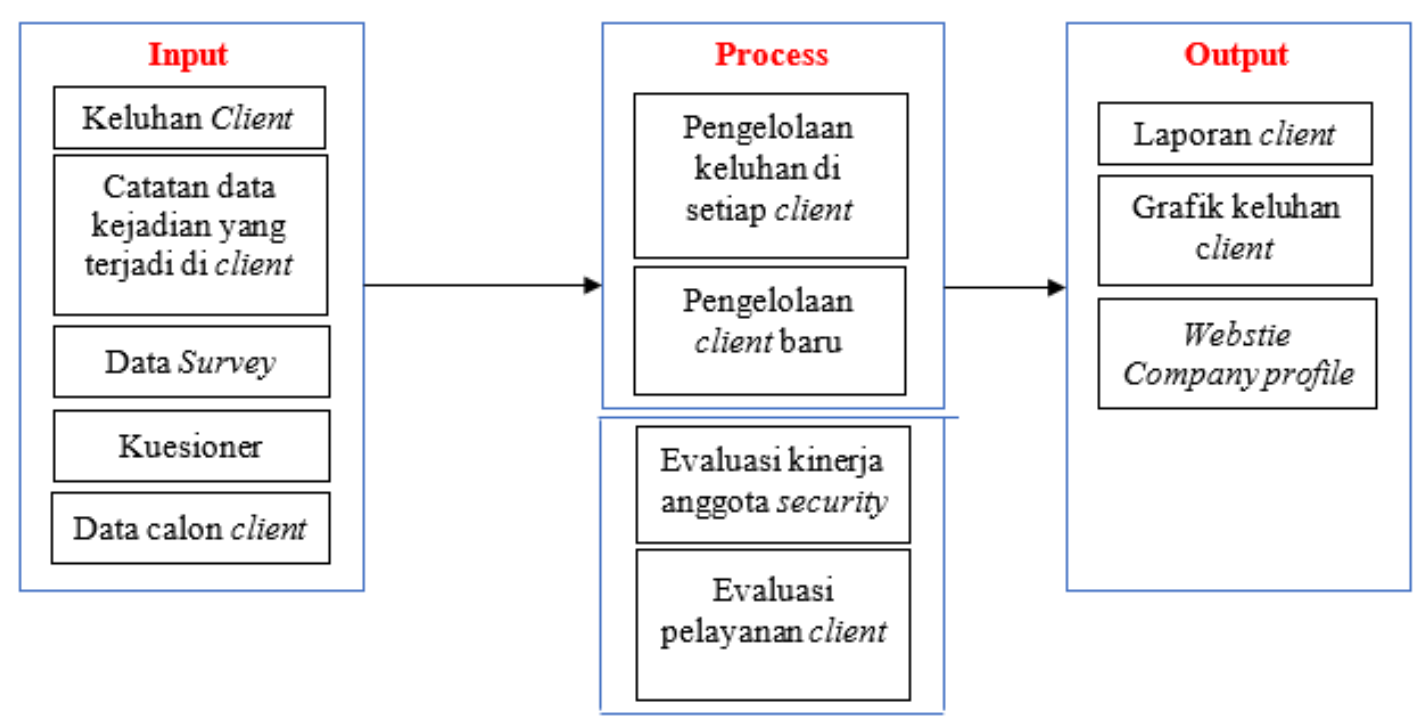

Gambar 2. Gambaran Rancangan Sistem yang akan dibangun secara singkat 


\subsection{Coding}

Sistem dibuat per tahap berdasarkan desain sistem yang telah dilakukan pada tahap sebelumnya. Bahasa pemrograman yang digunakan dalam pembangunan perangkat lunak ini yaitu PHP, dengan framework CI dan menggunakan database MySQL sebagai tempat penyimpanan data.

\subsection{Testing}

Pengujian yang dilakukan pada tahapan ini akan menggunakan Black Box Testing untuk mengetahui ketepatan sistem yang dibangun dengan sesuai rancangan. Black Box Testing berfokus pada spesifikasi fungsional dari sistem.

\section{HASIL DAN PEMBAHASAN}

Pada perancangan sistem merupakan tahapan merancang sistem berdasarkan flowmap sistem berjalan. Pembangunan sistem dilakukan dengan Unified Modeling Language (UML). Perancangan UML salah satunya yaitu rancangan business actor berisi informasi aktor-aktor yang akan terlibat langsung dengan sistem yang sesuai dengan rancangan. Aktor tersebut memiliki perbedaan hak akses dengan aktor yang lainnya. Deskripsi dari business actor yang terlibat dalam rancangan sistem electronic customer relationship management pada PT. Sapta Satria Jaya. Gambar 3 merupakan gambar Business actor pada sistem E-CRM

1. HRD memiliki hak akses untuk mengelola data client dan memonitoring client.

2. Korwil memiliki hak akses untuk memverifikasi pengajuan keluhan yangg dimasukkan oleh danru dan client, mengirim formulir keluhan dan kejadian kepada HRD.

3. Client memiliki hak akses mengajukan keluhan, melihat informasi absensi anggota.

4. Danru memiliki hak akses untuk menginputkan keluhan dan kerjadian yang terjadi pada client, dan menginputkan absensi anggota.

5. Marketing memiliki hak akses untuk mendapatkan client baru

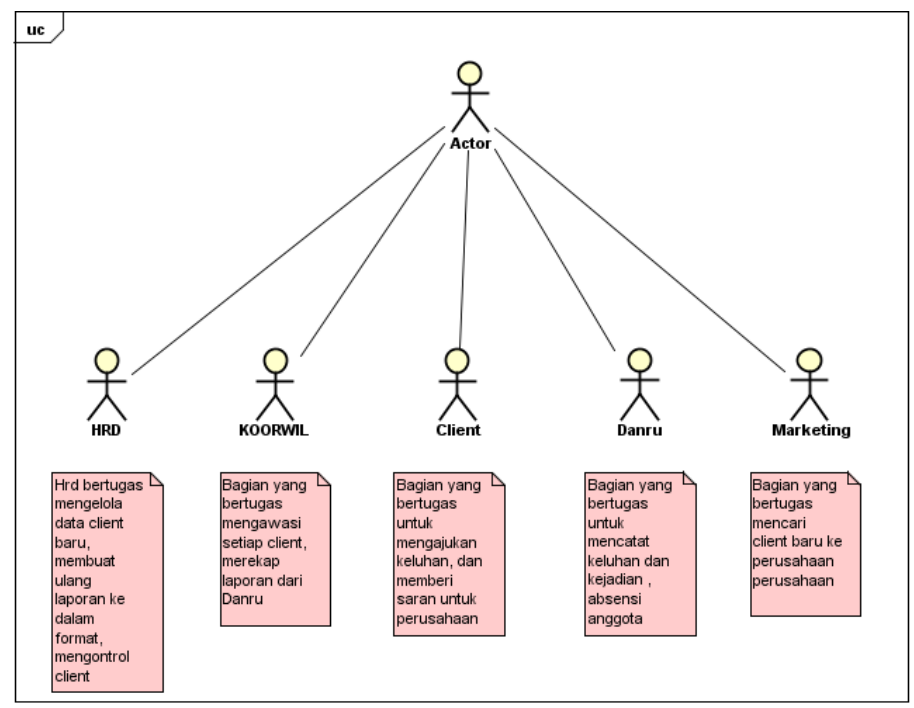

Gambar 3. Business Actor 
Use Case Diagram menggambarkan bagaimana aktor berinteraksi dengan sistem, dibuat sesuai proses bisnis yang telah dijelaskan pada analisis sistem yang sedang berjalan. Use Case ini memiliki sembilan Use Case utama yaitu kelola client, kelola user, kelola staf, pelayanan, kelola anggota, kelola keluhan, kelola kejadian, kelola keluhan, dan kelola laporan. Use Case Diagram terdapat pada Gambar 4.

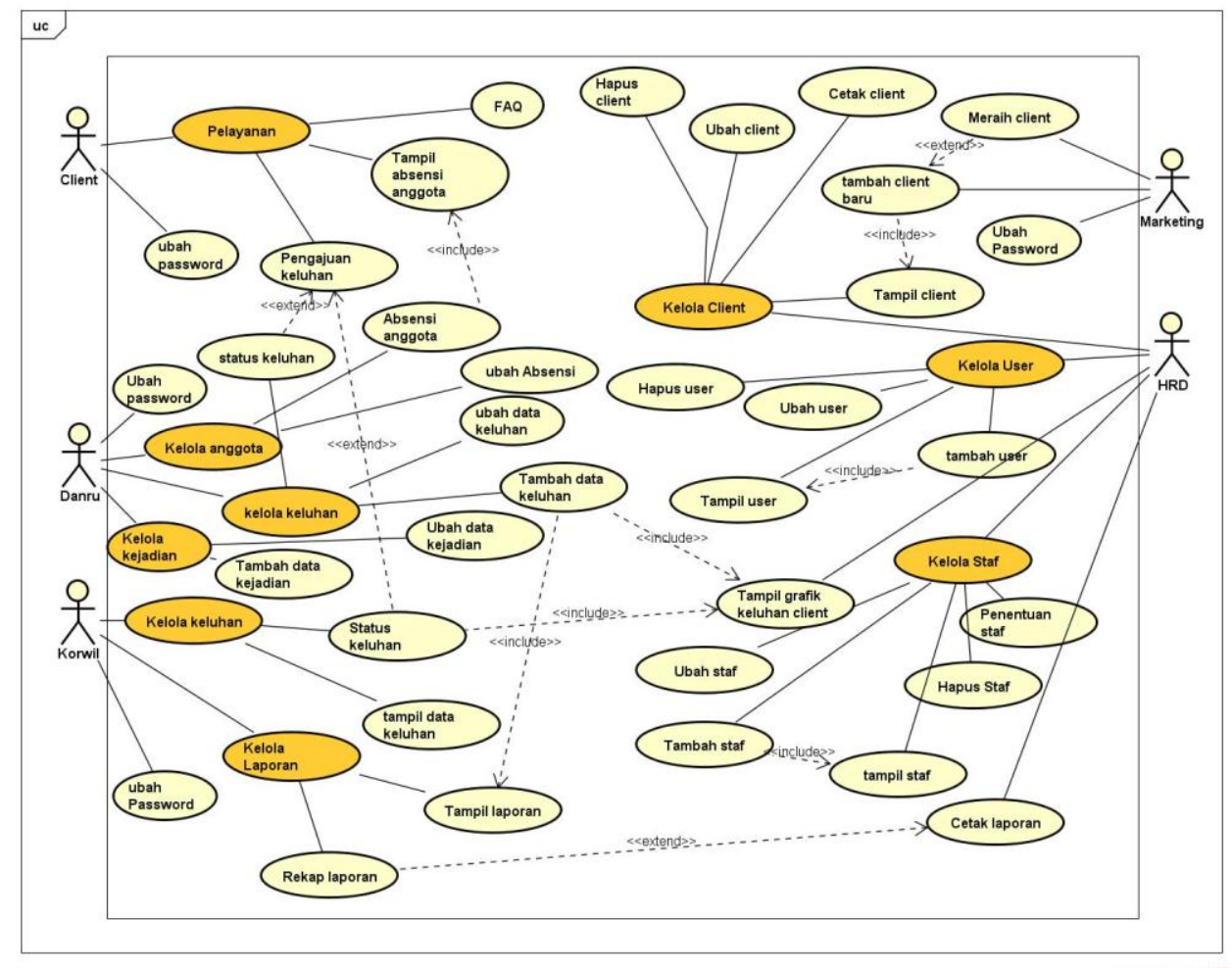

Gambar 4. Use Case Diagram

Class Diagram adalah Diagram yang menggambarkan bentuk cetakan dari setiap objek yang bekerja pada sistem. Sebuah class dapat merupakan keturunan dari class lain atau bagian dari class lain. Objek-objek yang bekerja pada sistem ini dibentuk dari setiap class yang ada. Class diagram terdapat pada Gambar 5.

Implementasi antarmuka sistem berbasis website dengan menggunakan framework codeigniter sebagai berikut :

1. Implementasi Antarmuka Login

Implementasi antarmuka login dapat login oleh HRD, Marketing, Korwil, Danru, dan Client. Terdapat pada Gambar 6. 
Pembangunan Sistem Electronic Customer Relationship Management (E-CRM) pada PT. Sapta Satria Jaya

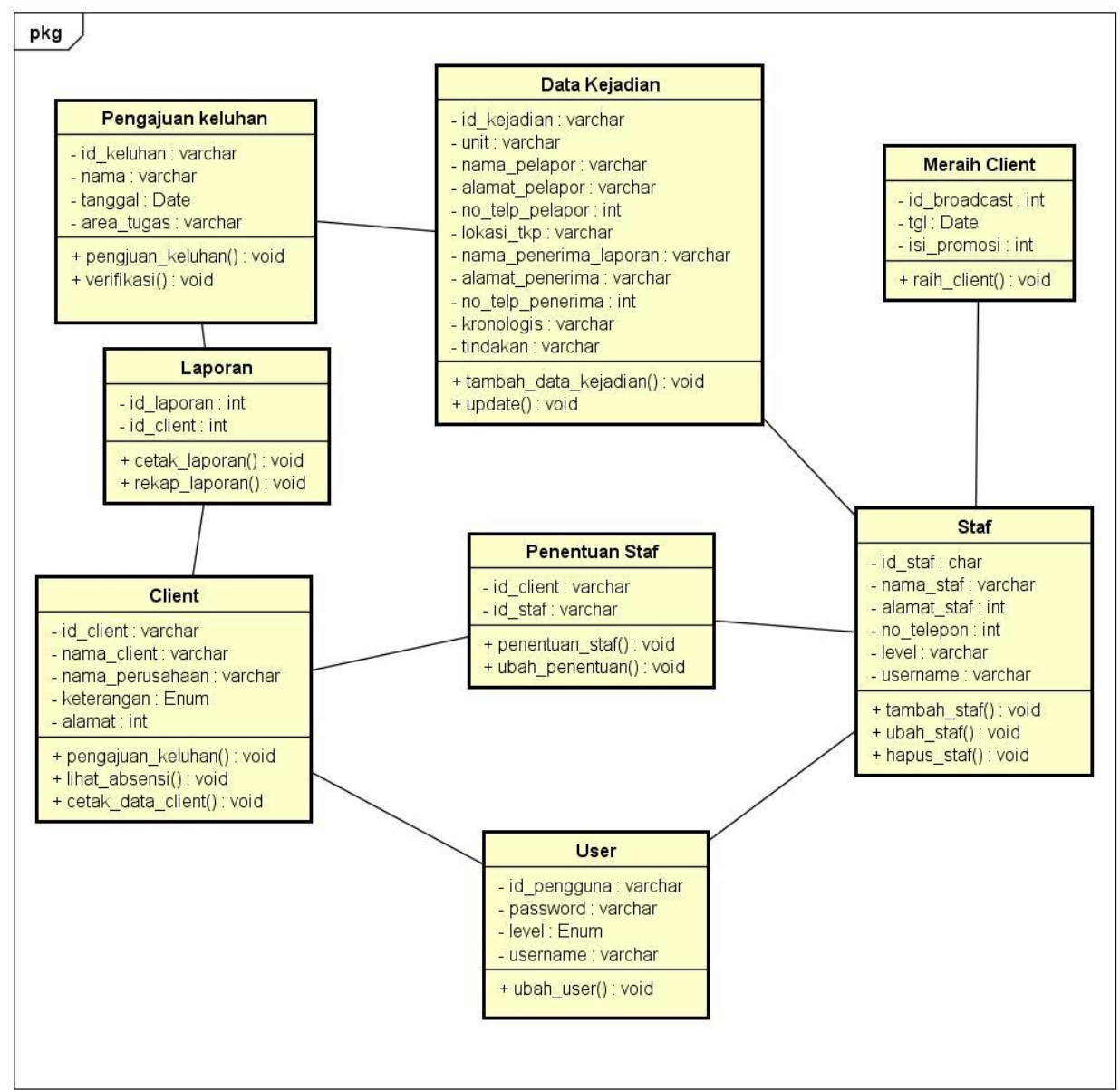

Gambar 5. Class Diagram

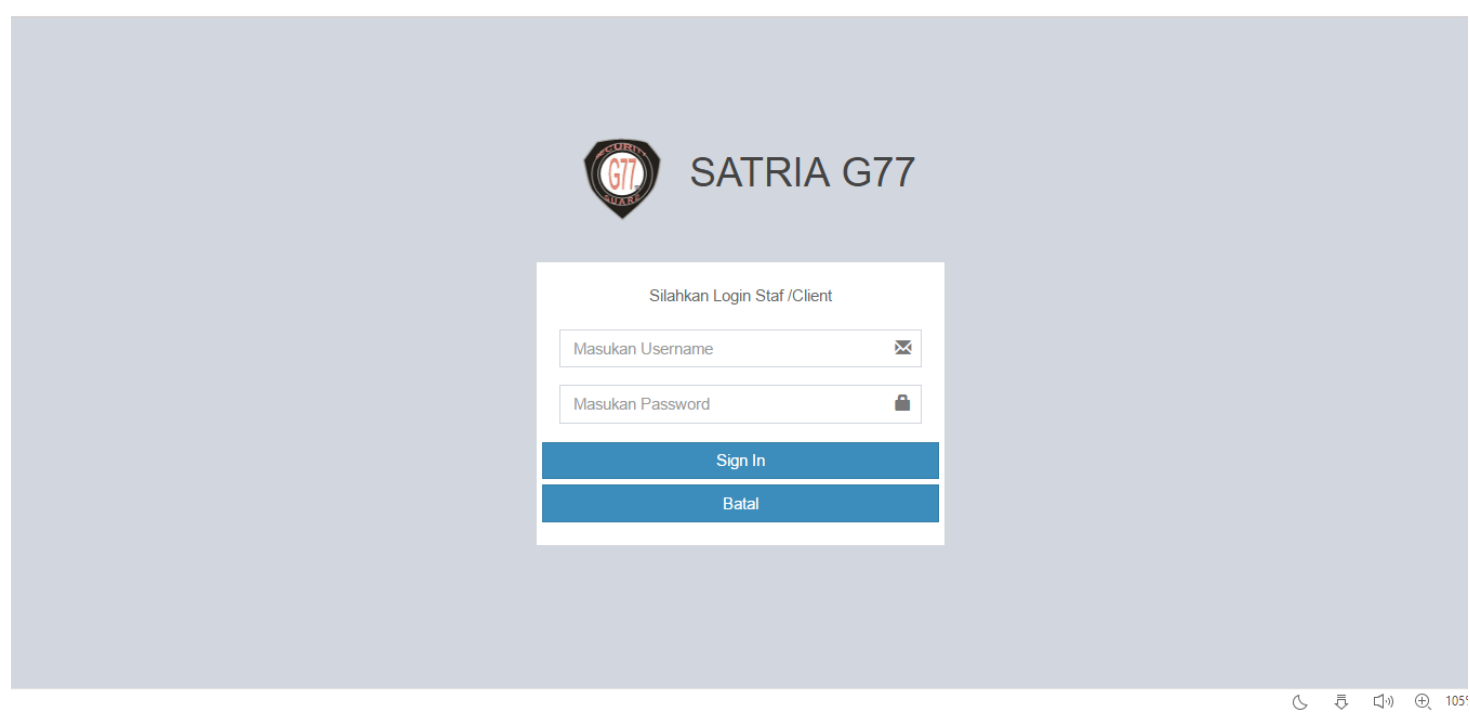

Gambar 6. Antarmuka Login

\section{Implementasi Antarmuka Setelah Login}

Implementasi antarmuka apabila HRD telah login, terdapat pada Gambar 7. 


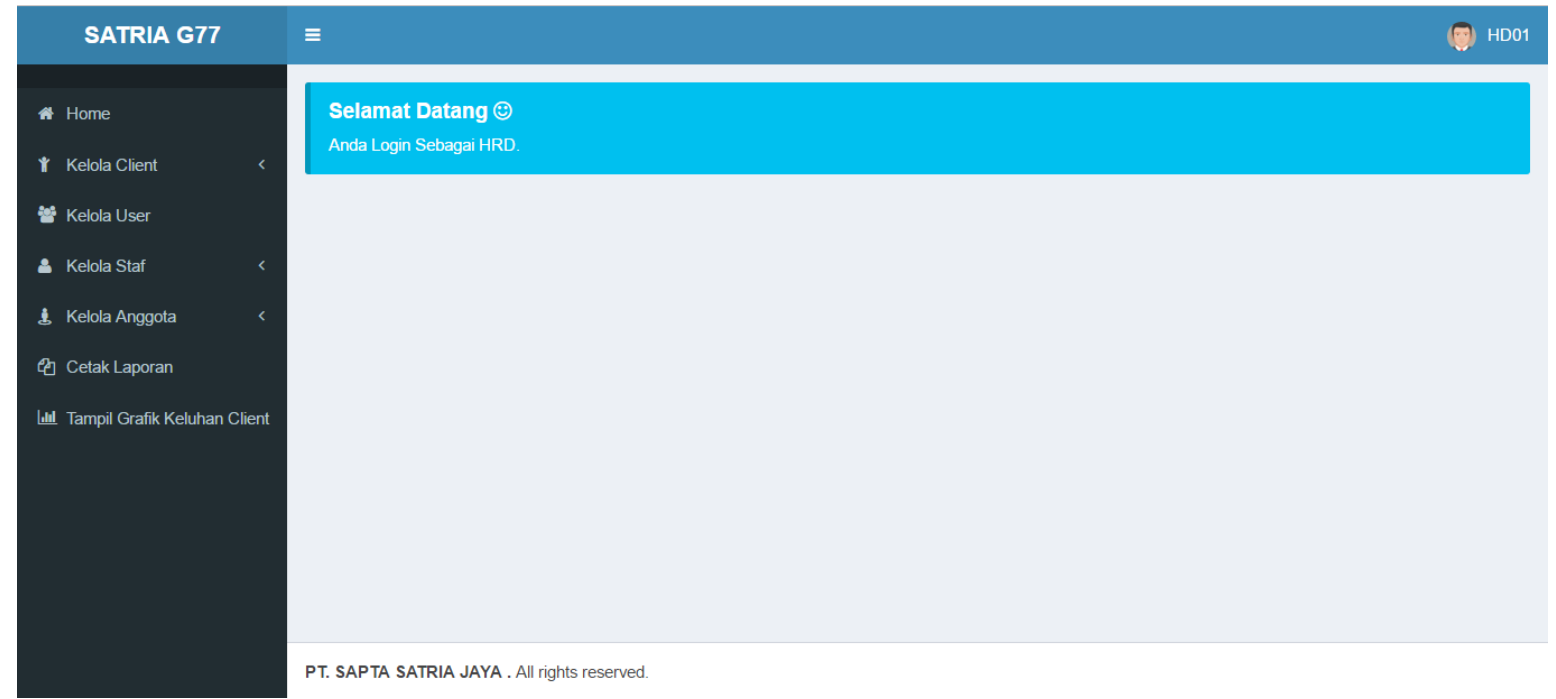

Gambar 7. Antarmuka setelah login

3. Implementasi Antarmuka Home

Implementasi antarmuka home HRD dapat melihat secara keseluruhan jumlah dari client, jumlah user yang aktif, jumlah staf, dan presentasi persen keluhan client. Terdapat pada Gambar 8.

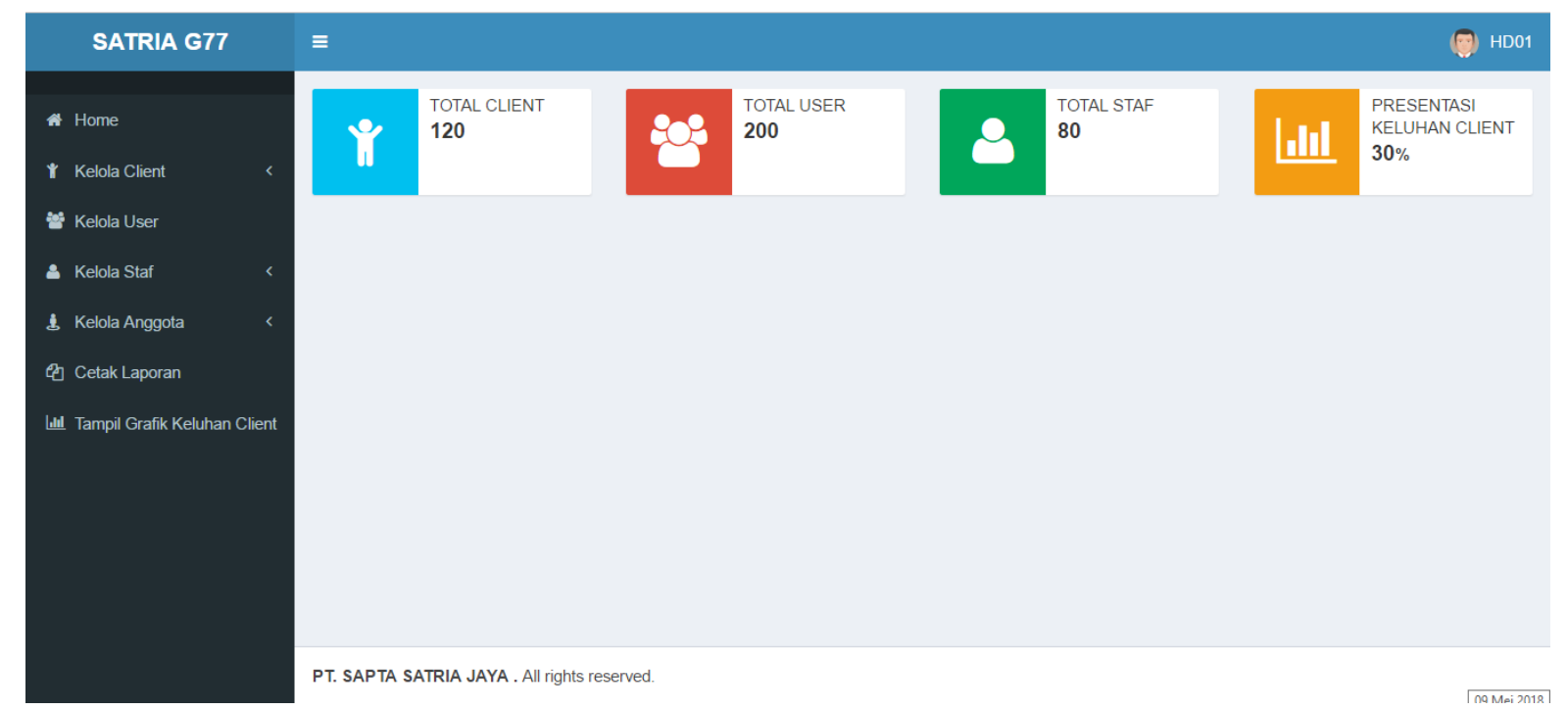

Gambar 8. Antarmuka Home

4. Implementasi Antarmuka Daftar Data Anggota

Implementasi antarmuka daftar data anggota menampilkan informasi anggota satpam dan menampilkan komandan regu (Danru), terdapat pada Gambar 9. 


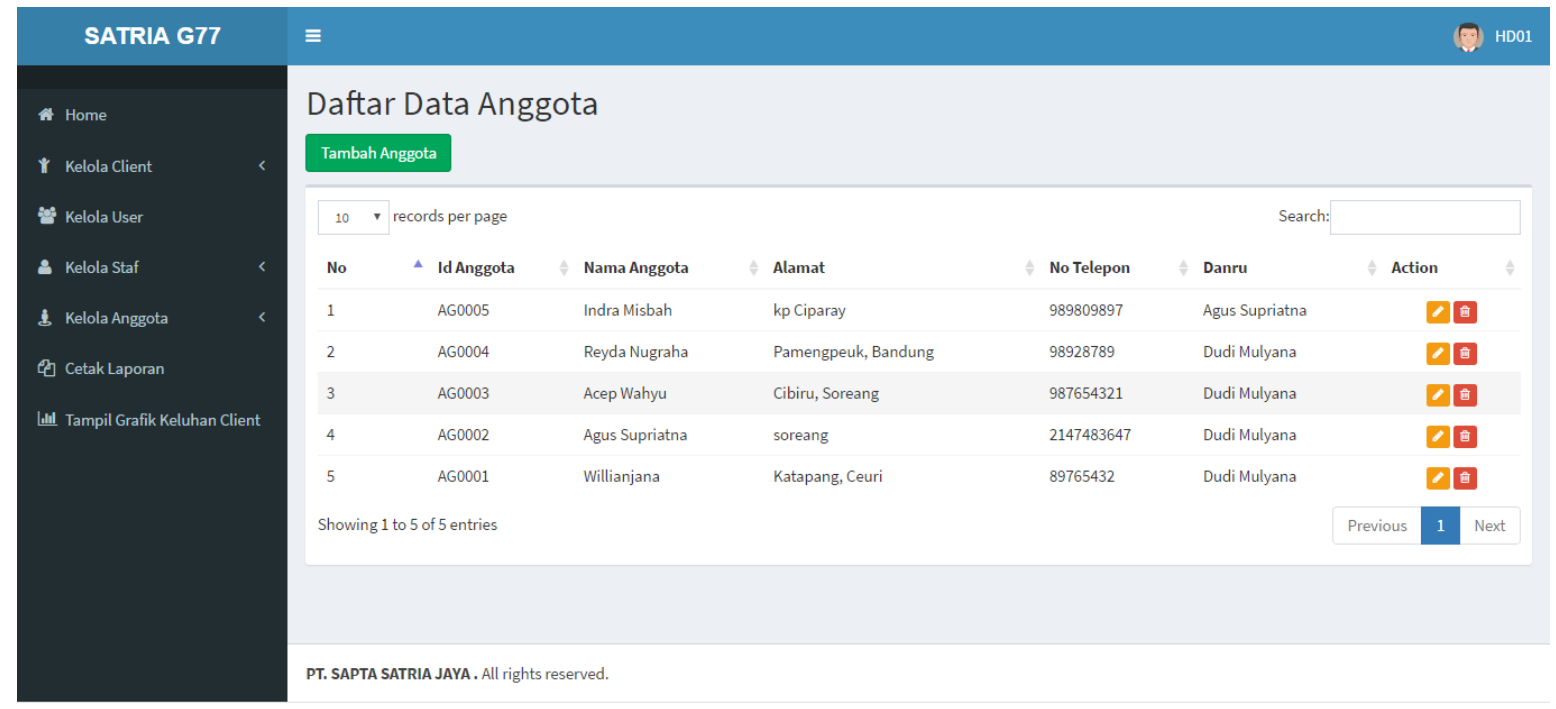

Gambar 9. Antarmuka Daftar Data Anggota

Pengujian ini bertujuan untuk menunjukkan keberadaan kesalahan pada Sistem E-CRM yang kemudian akan digunakan sebagai acuan perbaikan sehingga sistem yang dapat berfungsi dengan baik dan dapat befungsi sebagaimana mestinya.

Tabel 1. Pengujian Fungsional

\begin{tabular}{|l|l|l|l|}
\hline No & Fungsi & Presentase & Keterangan \\
\hline 1. & Login & $\begin{array}{l}\text { Dari 4 kasus yang diujikan pada } \\
\text { sistem untuk fungsi login, 4 } \\
\text { diantaranya berhasil }\end{array}$ & $\begin{array}{l}\text { Kasus terserbut menguji } \\
\text { validasi form apabila } \\
\text { sengaja password nya di } \\
\text { salahkan, menguji session, } \\
\text { menguji button batal, } \\
\text { menguji mengisi form } \\
\text { login dengan benar }\end{array}$ \\
\hline 2. & Home & $\begin{array}{l}\text { Dari 2 kasus pada saat pengujian } \\
\text { dan dinyatakan berhasil }\end{array}$ & $\begin{array}{l}\text { Kasus tersebut menguji } \\
\text { jumlah pengitungan data } \\
\text { client, jumlah staf, jumlah } \\
\text { user, dan presentasi grafik } \\
\text { keluhan mana saja yang } \\
\text { sering mengalami keluhan }\end{array}$ \\
\hline 3 & Kelola Anggota & $\begin{array}{l}\text { Dari 4 kasus pada saat pengujian } \\
\text { dan dinyatakan berhasil }\end{array}$ & $\begin{array}{l}\text { Kasus tersebut menguji } \\
\text { tambah data anggota baru, } \\
\text { ubah anggota, hapus } \\
\text { anggota, dan menampilkan } \\
\text { ata anggota ke dalam } \\
\text { tabel }\end{array}$ \\
\hline
\end{tabular}

\section{KESIMPULAN}

Berdasarkan pada hasil dari penelitian yang dilakukan dalam pembangunan sistem E-CRM dapat disimpulkan bahwa dengan adanya sistem E-CRM dapat menurunkan presentasi keterlambatan Danru menjadi $10 \%$ saat mengumpulkan laporan dan jalur birokrasi yang 
singkat, menjadikan perusahaan dapat mempertahankan client dan meraih client baru dengan pemberian informasi yang dibutuhkan oleh client dan proses pengontrolan client mana saja yang sering mengalami keluhan kinerja menjadikan evaluasi bagi perusahaan untuk meningkatkan pelayanan perusahaan.

\section{DAFTAR PUSTAKA}

\section{Rujukan Buku:}

F. S. Fajri Rakhmat U, Teknik Hebat Merancang Aplikasi Instan Berkualitas, Jakarta: PT Alex Media Komputindo, 2015.

\section{Rujukan Jurnal:}

A. P. Mardison, "Perancangan dan Pembuatan Aplikasi Customer Relationship Management pada koperasi pembangunan usaha sumber berbasis web," Jurnal KomTekInfo Fakultas IImu Komputer, Volume 2, No. 1, pp. 6-9, 2015.

R. Hidayat, "Sistem Informasi Ekspedisi Barang Dengan Metode Sistem Informasi Ekspedisi Barang Dengan Metode Sistem Informasi Ekspedisi Barang Dengan Metode Sistem Informasi Ekspedisi Barang Dengan Metode Sistem Informasi Ekspedisi Barang," Jurnal Sisfotek Global, no. ISSN : 2088 - 1762 Vol. 4 No. 2, pp. 23-30, 2014.

\section{Rujukan Prosiding:}

A. A. I. G. R. A. S. D. Wina Witanti, Analisis dan Desain Sistem Informasi, Bandung: Politeknik Telkom, 2009.

z. s. nima jafari, "The impact of cost,technology acceptance and employees 'satisfaction on the effectiveness of the electronic customer relationship," ComputersinHumanBehavior, pp. 1053-1066, 2016.

A. I. Wina Witanti, "Analisis Jejaring Sosial Menggunakan Social Network Analysis untuk membantu Social CRM bagi UMKM di CImahi," Semnas, pp. VI.29-VI.36, 2014.

J. N. A. I. H. Wina Witanti, "Pembangunan Sistem Customer Relationship Management di PT. Dirgantara Indonesia pada Bagian Metrology," Seminar Nasional Informasi dan Multimedia 2018, pp. 2.10-79-2.10-84, 2018.

S. e. n. Agus, "Perancangan Sistem Informasi Pelacakan Berbasis CRM untuk perusahaan jasa service center," Seminar Nasional Teknologi Informasi dan Multimedia 2014, pp. 3.01-7-3.01-12, 2014.

i. W. Albertus Januaris Kundre, "Penerapan Customer Relationship Management dengan dukungan teknolofi informasi pada PO.CHELSY," Seminar Nasional Teknologi Informasi dan Multimedia, pp. 28-7-28-12, 2013.

F. O. N. K. Wina Witanti, "Pembangunan Sistem Customer Relationship Management pada PT. Central Georgette Nusantara," Prosiding SNATIF, pp. 431-438, 2017. 